\title{
Life Cycle Assessment and Cost Evaluation of Emerging Technologies at Early Stages: The Case of Continuous Flow Synthesis of Rufinamide
}

\author{
Fabio Grimaldi ${ }^{1}$, Gerardo Antonio de Leon Izeppi ${ }^{2}$, Dirk Kirschneck ${ }^{2}$, Paola Lettieri ${ }^{1}$, Marc Escribà- \\ Gelonch $^{3,4}$, Volker Hessel ${ }^{3,5}$ \\ ${ }^{1}$ University College London; ${ }^{2}$ Microinnova Engineering GmbH; ${ }^{3}$ Eindhoven University of \\ Technology; ${ }^{4}$ Centre National de la Recherche Scientifique; ${ }^{5}$ The University of Adelaide
}

fabio.grimaldi@ucl.ac.uk

\begin{abstract}
In the pharma and fine chemical industries, the development of continuous flow technologies is a process intensification step of primary importance towards the manufacturing of high-quality products, while reducing the environmental impact and cost of production. The sustainability and profitability of a process can be measured through Life Cycle Assessment and cost evaluation. However, when applied to emerging technologies, these need to be performed at different stages of the process development in order to limit the uncertainties arising from the scale-up, and hence providing high-fidelity projections of environmental impacts and costs at larger scales. The output of the assessment can in fact vary significantly depending on the maturity of the technology and this translates into having different results at commercial scale compared to early estimations. Therefore, in this paper we perform an assessment at two different scales of production, lab and mini-pilot scale, with the aim of quantifying the uncertainties of the assessment related to the scale-up, identifying the hotspots of the system, and hence providing guidelines for the further steps of process development. The subject of the assessment is the continuous flow synthesis of Rufinamide. It is the first time that this synthesis is evaluated at pilot-scale. The results show that low yields in the cycloaddition drastically affect the waste management and the production of precursors, and hence increases environmental impacts and cost of production. This calls for the need of prioritizing the optimization of this synthesis step in order to deploy a green and economically competitive production technology.
\end{abstract}

KEYWORDS: Anticipatory assessment - Emerging technologies - Continuous flow synthesis Uncertainty - Life Cycle Assessment - Sustainability - Cost analysis

\section{INTRODUCTION}

Process intensification offers several benefits regarding process efficiency, the use of resources and therefore sustainability ${ }^{1-4}$. In the pharma and fine chemical industries, continuous flow (CF) technologies ${ }^{5-9}$ are considered good examples of process intensification, which are able to deliver high-quality products. These emerging technologies, however, are seldom used in industry because they are often not attractive to management at large scales due to economic or environmental reasons. Not all processes reach in fact commercial scale, and this translates into loss of human and capital resources. Furthermore, their development can be costly, time consuming and involve long procedures for their implementation ${ }^{10}$.

This article has been accepted for publication and undergone full peer review but has not been through the copyediting, typesetting, pagination and proofreading process, which may lead to differences between this version and the Version of Record. Please cite this article as doi: 10.1002/amp2.10043 
Therefore, emerging technologies need to be filtered from early stages to prevent waste of resources which lead to high costs and reduce competitiveness. To this end, the early screening and filtration of emerging technologies requires a high level of knowledge of the process. Such knowledge, however, is usually only obtained at later stages of their development.

This calls for the need of an "anticipatory" or "ex-ante" assessment, being able to provide a faithful rendering of the environmental impact ${ }^{11}$ and costs throughout the process development of an emerging technology ${ }^{12}$. A visual representation of this is shown in Figure 1.

This type of assessment should hence quantify the uncertainty and variability of the results depending on the scale ${ }^{13}$, and identify the 'hotspots' of the system on which focus the subsequent phases of the development.

To this end, in this paper we report the environmental impact and cost assessment of an intensified production technology that is still at the early stages of development: the CF synthesis of Rufinamide ${ }^{14-16}$, an anticonvulsant drug consumed worldwide for the treatment of epilepsy ${ }^{17}$. The latter is assessed at different scales, a lab scale and a mini-pilot scale (productivity of $7 \mathrm{~g} / \mathrm{h}$ and $47 \mathrm{~g} / \mathrm{h}$ respectively) in order to understand the effect of the scale-up on the environment and the costs. The low maturity of this CF system is taken into account by identifying the parameters of the synthesis (e.g operative conditions) that generate uncertainties in the results. These uncertainties are quantified by means of hotspot analysis and scenario analysis. All together, these provide a more accurate projection of the environmental impacts and costs of the system at larger scales. It is worth noting, that the scale of production of pharmaceuticals is relatively low compared to that of bulk chemicals, with the average mass of pharmaceuticals produced in a single plant being $10-10^{3}$ tonnes/year and $10^{4}-10^{6}$ tonnes/year for bulk chemicals ${ }^{18}$. Notwithstanding this, the mass of waste generated per mass of product (i.e. E factor ${ }^{19}$ ) has been estimated to be $25->100^{18}(>200$, according to other sources ${ }^{20}$ ) for pharmaceuticals, opposed to that of bulk chemicals having a $E$ factor of $<1-5^{18}$. This is partly a reflection of the increasing complexity of pharma products, necessitating multistep batch syntheses and large volumes of solvents ${ }^{18}$. Furthermore, the research for new pharmaceuticals involves intensive R\&D activities at lab scale and pilot scale with substantial resources allocated ${ }^{21}$. Therefore, the production of pharma products can have a large environmental footprint, in spite of contained volumes of product generated. This call for the need of assessments being able to capture the potential impact of a production process from the early stages of its development and render the latter more efficient.

To this end, the environmental impact assessment is undertaken using the Life Cycle Assessment (LCA) methodology. This is regulated by the International Standard Organization (ISO, $14040^{22}$ and $\left.14044^{23}\right)$; it enables the qualification and quantification of environmental impacts and identifies improvement options throughout the life cycle of a product, process or activity. In this paper, LCA is applied in an "anticipatory" ${ }^{24-29}$ fashion at the early stages of the development of the CF synthesis of Rufinamide.

It is the first time the LCA is undertaken on the production of Rufinamide at a pilot scale. To date, LCA has been performed on the CF production of Rufinamide only at lab scale ${ }^{30}$; this study analyzed the environmental profile of different Rufinamide synthesis pathways and reported a comparison of batch and CF routes to 2,6-difluorobenzyl azide (Rufinamide precursor).

No evaluation of the consequences of the scale-up of this technology has been published yet, and more generally, only few LCA studies have been published in literature on pilot scale productions ${ }^{28,31}$. To this end, the present study fills this gap by evaluating the effect of the scale-up of the CF synthesis of Rufinamide on environmental impacts and costs. As mentioned before, this is a critical aspect in the process development, and this assessment provides guidelines for the further steps of the 
process development, rendering the latter more efficient, less costly and preventing waste of resources.

With regards to the economic analysis, a preliminary evaluation of the CF synthesis of Rufinamide has been performed by Escriba et. $\mathrm{al}^{16}$. In the latter, the payback period (PBP) and cumulative cash flow (CCF) were used as main indicators. The analysis looked at the impact of the cost of the raw materials used in the process, the number of operators needed for the operation of the plant, and the capital investment. However, in this analysis the effect of variable yield of the synthesis was not evaluated thoroughly. In the present work, the latter is fully analyzed by considering the potential variation of the synthesis yield in the next steps of the process development, and how this will affect $\mathrm{PBP}$ and CCF.

The paper is structured as follow:

- Materials and Methods

The CF synthesis of Rufinamide is described and the assessment methodology is presented.

- Results and Discussion

This section reports the results of the LCA and cost assessment. These includes a scenario analysis, hotspot analysis and comparative analysis.

- Conclusions

Conclusions are drawn and opportunities for future works are discussed. 


\section{MATERIALS AND METHODS}

This section is divided into three parts. Firstly, the subject of the assessment, the CF synthesis of Rufinamide, is described in 'System Definition'. This offers an overview of the synthesis method, a description of the operative conditions adopted at different scales, and the process parameters on which the environmental impact and cost assessment focus on. Lastly, 'Environmental impact assessment' and 'Cost assessment' report a description of the methodology adopted and the calculation of the results.

\subsection{System Definition}

Rufinamide is antiepileptic drug used to treat the Lennox-Gastaut syndrome and it was originally developed by Novartis Pharma. Several batch processes and synthetic routes have been described in patents ${ }^{32-34}$. However, these processes hinge on the use of expensive raw materials (i.e. dipolarophiles), are often characterized by high consumption of solvents and involve purification steps that have a large impact on the environment as they increase the generation of wastes ${ }^{14}$. In order to improve the environmental impact and the economics of the process, a solvent-free and continuous plant was developed ${ }^{14-16,30}$. A schematic representation of the CF synthesis of Rufinamide is reported in Figure 2.

A description of each step of the synthesis is reported in the 'Supporting Information'. The CF process was originally developed at lab scale and it was later on scaled-up to a mini-pilot plant. Figure 2 provides also a list of the different operative conditions followed in the lab and mini-pilot systems. The plant operates solvent-free with exception of the Step 2, from the addition of $\mathrm{NaN}_{3}$ to the $\mathrm{L} / \mathrm{L}$ separator. As reported in previous publications ${ }^{14,16}$, the scale-up process can lead to different mass and heat transfer coefficients which can have an impact on the yield. To this end, the proposed assessment investigates on the effects that different operative conditions have on environmental impacts and costs. Furthermore, a scenario analysis is undertaken, considering as a variable the overall yield of the synthesis. Specifically, the Step 3 of the synthesis process has shown in the trials a significant variation in the yield due to fouling of the reactor. This is likely to be overcome with further optimization of the reactor design. To this end, the chosen scenarios range from the lowest overall yield observed in the mini-pilot system (47\%) to the best overall yield that was achieved in the lab scale (83\%), as listed in Figure 2.

\subsection{Environmental Impact Assessment}

The environmental impacts of the synthesis of Rufinamide are calculated for the lab and the minipilot scale. These are benchmarked against the environmental impact of the conventional batch synthesis. The results of the assessment of the CF system at mini-pilot scale are further analysed in a comparative analysis, showing the variations of the impacts depending on different overall yields and operative conditions. A hotspot analysis is also undertaken to identify the main causes of the environmental impacts.

Using a Life Cycle Assessment approach the phases described below have been followed:

\section{Life Cycle Inventory (LCl)}

This is an inventory analysis in which all the relevant inputs and outputs of the product system are quantified by means of data collection and calculation procedures (indicated by the ISO $14040^{22}$ ). By means of the $\mathrm{LCl}$, it is possible to understand in advance whether the resources utilization and releases to the environmental matrices will be relevant, or not. At the basis of the $\mathrm{LCl}$ there is the definition of the Functional Unit (FU), that quantifies the function of the product under study and provides a reference to which input and output data are normalized; in this study the selected FU is $1 \mathrm{~kg}$ of Rufinamide. 
The data for the $\mathrm{LCl}$ are quantified for each unit process included into the defined system boundaries (Figure 3). These are subdivided into macro systems: foreground and background. The foreground system is composed by the array of operations occurring in the production phase, and by the production of chemicals. The background system is composed by the set of operations and services that revolve around the synthesis, namely, electricity production, raw materials extraction, and waste disposal. Each process is defined by compiling the material and energy balance occurring in them through the standardized approach indicated in the ISO $14040^{22}$ and these includes:

- Energy inputs, raw materials, ancillary inputs, other physical inputs,

- Products, co-products and waste,

- Emissions to air, discharges to water and soil, and other environmental aspects

\section{Life Cycle Impact Assessment (LCIA)}

This phase translates the elementary flows described in the $\mathrm{LCl}$ (i.e. emissions or resource use) into an impact on the environment. LCIA results are expressed on the basis of the defined FU.

$\mathrm{LCl}$ and $\mathrm{LClA}$ were supported by the software tools GaBi ts 8.7 (SP36) professional + extensions (II, VI, IX, XVII) and Ecoinvent 3.5 (integrated SP36): the datasets are in compliance with the ISO $14044^{35}$, ISO $14064^{36}$ and ISO $14025^{37}$ standards. In general, environmental impacts were estimated using a cradle-to-gate boundary for European production: in other words the activities that compose the life cycle (e.g electricity production) are region-specific and are modelled on the basis of European activities. LCIA was conducted applying the methodology "ReCiPe 2008 " by Goedkoop ${ }^{38}$ et al. in accordance with other studies ${ }^{30}$ on Rufinamide production, in order to render coherent the benchmark with previous results. The results are expressed through impact categories (see 'Supporting Information) that were addressed at the midpoint level. LCIA methods essentially model the environmental mechanism that underlies each of the impact categories as a cause-effect chain starting from the environmental intervention (emission or physical interaction) all the way to its impact. To this end, the impact can be expressed through midpoint and endpoint methods, depending on type of output the analysis is meant to provide (i.e. increased chemical concentration in a lake vs extinction of species). As a general rule, the further the outcome of the assessment is expressed in the cause-effect chain, the more the results can be biased. In the present study, the chosen LCIA method imply a midpoint level assessment in order to minimize errors.

\subsection{Cost Assessment}

The objective of performing a cost assessment is to provide enough information to make investment decisions. Besides selecting technologies with the biggest potential of economic return, early assessments can be used to assess risks, uncertainties or potential areas of improvement. In this paper we considered two indicators in the cost evaluation of the continuous plant: the payback period (PBP) and the cumulative cash flow (CCF). In the assessment, several scenarios are investigated. These scenarios take into account the uncertainty of the cost of the raw materials, total investment costs and number of operators. Complementing the previous analysis ${ }^{16}$, the impact of yield is evaluated under the same assumptions: straight line depreciation, useful life equal to 10 , salvage cost of $0 \%$, tax rate of $32 \%$, interest rate of $0 \%$. Furthermore, the same bulk prices are assumed.

At this stage, it is not possible to estimate additional costs such as regulatory and cleaning procedures. Consequently, it was assumed an additional $10 \%$ to the total costs (capital investment and raw material costs) to take into consideration these uncertainties, as reported by Escriba et. $\mathrm{al}^{16}$. 
With regards to calculations, the PBP is a methodology that estimates the amount of time to recover the investment, while the CCF estimates the sum of the cash flows in a determined period of time.

The PBP can be determined with Equation ${ }^{39}$.

$$
P B P=\frac{C_{T C}}{A_{N C I}}
$$

Where $A_{N C I}$ represents the annual cash income, $C_{T C}$ the new investment. The $A_{N C I}$ can be determined with Equation $2^{39}$.

$$
A_{N C I}=A_{C S}-\left(A_{C S}-A_{B D}\right) t
$$

Where $A_{C S}$ represents the annual cost savings, $A_{B D}$ the balance sheet depreciation and $t$ the tax rate. The CCF can be determined by the sum of $A_{N C I}$ in the period analyzed.

The evaluated scenarios use the following yields and reactant ratios (refer to Figure 2 for the synthesis steps):

- Ideal plant, $100 \%$ yield and ratio of all reactants equal to 1 .

- Lab plant, $\mathrm{HCl}: 2,6$-difluorobenzyl alcohol=1.2 and yield 99\%; $\mathrm{NaN}_{3}: 2,6$-difluorobenzyl chloride $=1.5$ and yield $98 \%$; methyl trans-3-methoxyacryate:2,6-difluorobenzyl azide $=1.5$ and yield $86 \%$.

- Mini-pilot plant, $\mathrm{HCl}: 2,6$-difluorobenzyl alcohol=4 and yield 90\%; $\mathrm{NaN}_{3}: 2,6$-difluorobenzyl chloride=1.6 and yield 99.4\%; methyl trans-3-methoxyacryate:2,6-difluorobenzyl azide=1.5 and yield $93 \%$.

- Worst case scenario, $\mathrm{HCl}: 2,6$-difluorobenzyl alcohol=2 and yield 90\%; $\mathrm{NaN}_{3}: 2,6-$ difluorobenzyl chloride=1.6 and yield 99.4\%; methyl trans-3-methoxyacryate:2,6difluorobenzyl azide $=1.5$ and yield $47 \%$. 


\section{RESULTS AND DISCUSSION}

\subsection{Environmental impacts}

The environmental impact of the CF synthesis of Rufinamide at lab scale and at mini-pilot scale are presented in Figure 4. These are normalized on the basis of the environmental impact of the CF synthesis at lab scale (baseline, in orange) and are expressed for each of the impact categories listed in the figure (in accordance with the work of Ott et al. ${ }^{30}$ ). Three scenarios are considered for the mini-pilot setup, referring to different process yields as a result of the uncertainties of the experimental results obtained in Step 3 (see 'System Definition, Figure 2'). These yields represent a pessimistic scenario (47\%) in which the observed fouling issue cannot be mitigated, an optimistic scenario $(83 \%)$ in which the overall yield of the mini-pilot system is equal to the overall yield observed in the lab system, and a mid-way scenario (65\%). Furthermore, the proposed scenarios allow a potential deviation of $20 \%$ from the baseline (reported in Figure 2), for each one of the chemicals and operative conditions involved in the cycloaddition step, namely, methyl-trans-3methylacrylate, methanol, $\mathrm{NH}_{3}$, energy generation and waste management.

As shown in Figure 4, the environmental impact of the CF synthesis is significantly lower compared to the batch synthesis (red lines in the graph). With specific regards to the CF synthesis, the impacts associated to the mini-pilot system are generally higher compared to the lab system, in all the impact categories analyzed. To this end, low yields in Step 3 translates into higher environmental impacts. A detailed analysis on the primary causes of such increase is reported later in the hotspot analysis. It is worth noting that the optimistic scenario (83\%) for the mini-pilot scale has still slightly higher ( 6\% on average) environmental impacts than lab CF system in all the impact categories. This additional impact can be looked at as the effect of the different operative conditions followed in the mini-pilot system, namely operative temperature and precursor ratios.

A hotspot analysis of the environmental impact of the lab and mini-pilot CF system is reported in Error! Reference source not found.. This looks at the contributions of the activities present in the life cycle of the synthesis of Rufinamide to the overall environmental impact. Following a similar approach as in Figure 4, the baseline is the environmental impact of the lab system ${ }^{30}$ and the results of the LCA of the mini-pilot system are normalized accordingly.

The production of 2-6-diflorobenzyl alcohol takes on average more than $50 \%$ of the environmental impact of the CF synthesis of Rufinamide in all the impact categories. This compound is the main precursor and hence its impact is hardly mitigatable without changing the synthesis method or the way it is produced. Methanol and methyl trans-3-methoxyacrylate production, and energy generation take a significant share of the impact in Fossil Depletion Potential, Ozone Depletion Potential and Natural land transformation potential. Waste management is also a major contributor to the environmental impact of the systems. The waste generated is classified as hazardous waste and it is consequently disposed via incineration route that contributes to increase the impact especially in Global Warming Potential, Ozone Depletion Potential and Terrestrial Ecotoxicity Potential. To this end, the CF process requires lower volumes of solvents across the CF synthesis compared to conventional multi-step batch synthesis. The generation of waste is hence reduced, and this emerges clearly by looking at indicators such as E factor and solvent rate. These look respectively at the ratio of the total mass of waste to the mass of the isolated product, and the total mass of solvent to the mass of isolated product. In the CF process, both indicators are effectively reduced by a factor of 3.5 on average compared to the batch synthesis, with the final value being $17 \pm 2$ and 19 \pm 3 respectively ${ }^{30}$. From a wider perspective, the $E$ factor of the CF production of Rufinamide falls below the typical range of $E$ factors of pharma products ${ }^{18,20}$, attesting the reduction of the environmental footprint of the production process of Rufinamide when CF technology is used. 
Consequently, the CF synthesis emerges as a valid alternative to the batch synthesis of Rufinamide, and this should incentivize further efforts towards its deployment at commercial scale. Because of the potentialities shown in the efficient use of solvents and management of wastes, CF technologies could contribute, more in general, to reduce the environmental impact of other production processes in the pharma industry that still hinge on batch manufacturing. However, the results of this work cannot be generalized, and case-specific anticipatory assessments are needed in order to evaluate the impact of $\mathrm{CF}$ technologies on other manufacturing processes.

It is worth noting that as the overall yield of the CF mini-pilot synthesis of Rufinamide decreases, the environmental impact arising from the production of chemicals and waste management drastically increases as a consequence of additional quantities of chemicals required and the higher volume of waste produced per $\mathrm{kg}$ of Rufinamide. When the effect of the synthesis yield is excluded, it is possible capture further effects of the scale-up. This can be achieved by looking at the impact of the mini-pilot system (83\%) and comparing it with the impact of the lab system in Figure 5 . These two systems have the same overall yield but different operative conditions (see Figure 2 in 'System Definition'). On a closer look, the additional environmental impact of the mini-pilot system -less than $6 \%$ on average- results to be due to the production of $\mathrm{HCl}$ and energy generation. In other words, the main factors that contribute to the additional environmental impact of the mini-pilot plant are hence the higher ratio of $\mathrm{HCl}: 2,6$-difluorobenzyl alcohol in the Step 1 of the synthesis, which is circa 3.3 times higher compared to the lab scale, and higher reaction temperatures. The excess of $\mathrm{HCl}$ also contributes to generate a higher volume of wastes. These drawbacks could be theoretically mitigated by implementing a recirculation system, and hence avoiding part of the impact arising from incineration activities. The feasibility of this option has not been proved yet. However, a successful implementation would reduce the environmental impact of the CF mini-pilot scale, hence potentially matching the environmental impact of the CF lab system. To this end, it is worth noting that the CF synthesis at mini-pilot scale showed on average a lower environmental impact than the batch synthesis (Figure 4) also in the worst-case scenario ( $47 \%$ yield). From the LCA perspective, the CF synthesis would enable savings of environmental impact in each of the impact categories of the analysis, and it is therefore advisable that this production technology is adopted.

Operative conditions, energy consumption, waste management and synthesis yield emerged as the most relevant aspects to factor into the assessment of the scale-up. To this end, the latter is well summarized in Error! Reference source not found. that reports the effect of these factors on Global Warming Potential and Human Toxicity Potential.

It is worth remembering that Step 3 is still to be optimized in the mini-pilot system and hence there is room for improvement. As reported in the section 'System definition', the main issue is the fouling of the reactor. This can be overcome through further optimization of the reactor's design without impacting on the operative conditions of the system. By looking at Figure 6 , it is clear that low yields in the Step 3 of the synthesis highly affect the environmental impact of the system in the selected impact categories. In the light of this, the optimization of this step should be prioritized for the development of a low impacting production system in the next phases of the scale-up.

\subsection{Costs}

The reduction of the cost of the raw materials is the main business driver for the CF synthesis of Rufinamide. The analysis considered two plants (batch and CF) with an equal capacity of 10 ton/y. The yearly costs of the raw materials had been estimated to be $\$ 924 k$ and $\$ 1432 k$ for the batch and continuous plant respectively ${ }^{16}$. The bulk price of the raw materials was estimated using the correlation proposed by Hart et. al as seen in Eq. $3^{40}$. This equation estimates the bulk price of the products based on the price at lab scale, where the index $B$ represents the commercial scale and $l$ 
lab scale, $P$ represents the price, and $Q_{l}$ is the amount of grams at lab scale and $Q_{B}$ is a constant equal to $60 \mathrm{lb}$.

$$
P_{B}=P_{l}\left(\frac{Q_{B}}{Q_{l}}\right)^{-0.75}
$$

The previous cost estimations considered a fixed overall yield of $80 \%$ for the continuous plant. To this end, Figure 7 reports the annual expenditure on raw materials considering the potential variation in yields.

The scenario referring to pilot scale with $47 \%$ yield has the highest raw materials costs as it would be expected (lowest yield, worst case scenario). In this scenario, the annual expenses are in fact even higher than the annual expenses estimated for the batch process without considering recirculation of the reagents ${ }^{16}$. However, the estimation of the batch process is based on results at lab scale and no information was found at larger scales ${ }^{34}$.

Figure 7 also highlights the importance of having an optimized yield in the Step 3 of the synthesis. This results having a great impact on the use of raw materials, which take the highest share of the total costs. Additionally, Figure 7 shows the impact of the uncertainty on the cost estimation for each single raw material. It is observed that $\mathrm{HCl}$ (gas) has the highest impact and potential savings. This result requires as a next step to determine the commercial price of this specific raw material. In case the actual prices do not deviate greatly from the estimated ones, it could be helpful to take a step back and rethink if $\mathrm{HCl}$ (aq.) could be used instead as a mean to reduce costs even further, which has already been proven to be feasible before ${ }^{15}$. This approach would make a compromise between profitability and sustainability of the process $(\mathrm{HCl}$ in liquid phase produces water as waste).

Figure 8 shows the CCF under different case scenarios. Figure 8 also shows the impact on uncertainty of the raw materials costs ( $\pm 10 \%)$ of the CF plant.

The worst-case scenario (yield $47 \%$ ) does not provide a positive CCF under the assumptions analyzed in most of the scenarios evaluated. Additionally, without considering the worst-case scenario, the PBP was below 4-5 years in most of the cases. The cost of the raw materials is expected to have the biggest impact on the plant as reported by Escriba et al. ${ }^{16}$ and small variations on the estimations can have a major impact on the profitability of the project and it highlights the need to improve the yield of the third reaction step and to estimate as accurate as possible the cost of the raw materials.

\section{CONCLUSIONS}

We performed a life cycle assessment and cost evaluation of the continuous flow synthesis of Rufinamide at a lab scale and a mini-pilot scale. It is the first time that this synthesis is evaluated at pilot-scale. To this end, a scenario analysis and a hotspot analysis were undertaken to investigate the variation of the results and to identify the key parameters of the synthesis.

The assessment shows that, under the same overall yield, the CF mini-pilot plant has marginally higher environmental impacts and costs per kg of Rufinamide produced compared to the CF lab system. The mini-pilot plant adopts higher operative temperatures and ratio of reactant-to-precursor that translate into larger quantities of chemicals processed, additional energy consumption, and hence increased costs and effect on the environment. The increase though is marginal and the environmental impact and costs of the CF synthesis of Rufinamide at pilot scale remain significantly lower compared to a conventional batch synthesis. The lower impact stems in large part from the generation of waste, which is effectively mitigated in the CF system. In the latter the E factor is significantly lower than a conventional batch synthesis, and more generally falls below the typical range of $E$ factors of pharma products. In light of this, it is hence advisable that the CF production 
technology is adopted in place of the conventional batch synthesis of Rufinamide. However, the last step of the CF synthesis- the cycloaddition - has a strong effect on the performances of the minipilot plant and hence emerges from the assessment as the key factor for achieving low environmental impacts and generating good return on investment. Therefore, the next phase of the process development should prioritize the optimization of the cycloaddition step.

On the whole, the findings of this paper highlight the need for a continuous assessment on emerging technologies during the early stages of their development. As shown in the paper, this type of assessment provides insights on their optimization and it can be used as the basis for the screening and the selection of these technologies along process conditions and potential raw materials. We hence envisage the application of this approach to other emerging technologies with the aim of reducing waste of resources and capitals in the process development.

\section{ACKNOWLEDGMENTS}

This project has received funding from the European Union's Horizon 2020 research and innovation program under the Marie Sklodowska-Curie grant agreement no.721290.

\section{REFERENCES}

1. Van Gerven, T. \& Stankiewicz, A. Structure, Energy, Synergy, Time?The Fundamentals of Process Intensification. Ind. Eng. Chem. Res. 48, 2465-2474 (2009).

2. Raey, D., Ramshaw, C. \& Harvey, A. Process Intensification: Engineering for efficiency, sustainability and flexibility. (2013).

3. Stankiewicz, A. I. \& Moulijn, J. A. Process Intensification: Transforming Chemical Engineering. Chem. Eng. Prog. 22-34 (2000).

4. European Union's EU Framework Programme for Research and Innovation Horizon 2020. COSMIC - European Training Network for Continuous Sonication and Microwave Reactors. https://cosmic-etn.eu/ (2016).

5. Elvira, K. S., Casadevall i Solvas, X., Wootton, R. C. R. \& de Mello, A. J. The past, present and potential for microfluidic reactor technology in chemical synthesis. Nat. Chem. 5, 905-15 (2013).

6. Kralisch, D. \& Kreisel, G. Assessment of the ecological potential of microreaction technology. Chem. Eng. Sci. 62, 1094-1100 (2007).

7. Roberge, D. M., Gottsponer, M., Eyholzer, M. \& Kockmann, N. Industrial design, scale-up, and use of microreactors. Chim. Oggi 27, 8-11 (2009).

8. McGlone, T. et al. Oscillatory Flow Reactors (OFRs) for Continuous Manufacturing and Crystallization. Org. Process Res. Dev. 19, 1186-1202 (2015).

9. Lawton, S. et al. Continuous crystallization of pharmaceuticals using a continuous oscillatory baffled crystallizer. Org. Process Res. Dev. 13, 1357-1363 (2009).

10. Patel, A. D. et al. Sustainability assessment of novel chemical processes at early stage: application to biobased processes. Energy Environ. Sci. 5, 8430 (2012).

11. Klöpffer, W. et al. Nanotechnology and Life Cycle Assessment. A systems approach to Nanotechnology and the environment: Synthesis of Results Obtained at a Workshop Washington, DC 2-3 October 2006. (2007).

12. Curran, M. A. Report on Activity of Task Force 1: Data Registry - Global Life Cycle Inventory Data Resources. Int. J. Life Cycle Assess. 11, 284-289 (2006). 
13. Gavankar, S., Suh, S. \& Keller, A. A. The Role of Scale and Technology Maturity in Life Cycle Assessment of Emerging Technologies: A Case Study on Carbon Nanotubes. J. Ind. Ecol. 19, 51-60 (2015).

14. Borukhova, S., Noël, T., Metten, B., de Vos, E. \& Hessel, V. Solvent- and Catalyst-Free Huisgen Cycloaddition to Rufinamide in Flow with a Greener, Less Expensive Dipolarophile. ChemSusChem 6, 2220-2225 (2013).

15. Borukhova, S., Noël, T., Metten, B., de Vos, E. \& Hessel, V. From alcohol to 1,2,3-triazole via a multi-step continuous-flow synthesis of a rufinamide precursor. Green Chem. 18, 4947-4953 (2016).

16. Escribà-Gelonch, M., de Leon Izeppi, G. A., Kirschneck, D. \& Hessel, V. Multistep Solvent-Free $3 \mathrm{~m} 2$ Footprint Pilot Miniplant for the Synthesis of Annual Half-Ton Rufinamide Precursor. ACS Sustain. Chem. Eng. 7, 17237-17251 (2019).

17. World Health Organization. World Health Organization Epilepsy: Key facts. www.who.int/mediacentre/factsheets/fs999/en.

18. Dunn, P. J., Wells, A. \& Williams, M. T. Green Chemistry in the Pharmaceutical Industry. (Wiley-VCH, 2010).

19. Alfonsi, K. et al. Green chemistry tools to influence a medicinal chemistry and research chemistry based organisation. Green Chem. 10, 31-36 (2008).

20. Martins, J. Improving Sustainability in Pharmaceutical Manufacturing. https://www.pharmaceuticalprocessingworld.com/improving-sustainability-inpharmaceutical-manufacturing/ (2016).

21. Halliday, R. G., Drasdo, A. L., Lumley, C. E. \& Walker, S. R. The allocation of resources for R\&D in the world's leading pharmaceutical companies. $R$ D Manag. 27, 63-77 (1997).

22. ISO. ISO 14040:2006. (2016).

23. International Organization for Standardization. ISO 14044:2006 Environmental managementLife cycle assessment - Requirements and guidelines. (2006).

24. Villares, M., Işıldar, A., van der Giesen, C. \& Guinée, J. Does ex ante application enhance the usefulness of LCA? A case study on an emerging technology for metal recovery from e-waste. Int. J. Life Cycle Assess. 22, 1618-1633 (2017).

25. Wender, B. A. et al. Illustrating anticipatory life cycle assessment for emerging photovoltaic technologies. Environ. Sci. Technol. 48, 10531-10538 (2014).

26. Schrijvers, D. L., Leroux, F., Verney, V. \& Patel, M. K. Ex-ante life cycle assessment of polymer nanocomposites using organo-modified layered double hydroxides for potential application in agricultural films. Green Chem. 16, 4969-4984 (2014).

27. Ravikumar, D., Seager, T. P., Cucurachi, S., Prado, V. \& Mutel, C. Novel Method of Sensitivity Analysis Improves the Prioritization of Research in Anticipatory Life Cycle Assessment of Emerging Technologies. Environ. Sci. Technol. 52, 6534-6543 (2018).

28. Cucurachi, S., Van Der Giesen, C. \& Guinée, J. Ex-ante LCA of Emerging Technologies. Procedia CIRP 69, 463-468 (2018).

29. Roes, A. L. \& Patel, M. K. Ex-ante environmental assessments of novel technologies-improved caprolactam catalysis and hydrogen storage. J. Clean. Prod. 19, 1659-1667 (2011).

30. Ott, D., Borukhova, S. \& Hessel, V. Life cycle assessment of multi-step rufinamide synthesis from isolated reactions in batch to continuous microreactor networks. Green Chem. 18, 1096- 
$1116(2016)$.

31. Piccinno, F., Hischier, R., Seeger, S. \& Som, C. From laboratory to industrial scale: a scale-up framework for chemical processes in life cycle assessment studies. J. Clean. Prod. 135, 10851097 (2016).

32. Portmann, R. US 6156907 (Novartis). (2000).

33. Attolino, E., Colombo, L., Mormino, I. \& Allegrini, P. US 8198459 B2 (Dipharma Francis). (2012).

34. Kankan, R. N. US 8183269 B2 (Cipla). (2012).

35. ISO 14044:2006. Environmental management - Life Cycle Assessment - Requirements and Guidelines. (2018).

36. ISO. ISO 14064-1:2018. (2018).

37. ISO. ISO 14025:2006. (2015).

38. Goedkoop, M. et al. ReCiPe 2008. A life cycle impact assessment method which comprises harmonised category indicators at the midpoint and the endpoint level. First edition (revised) report I: characterisation. Report I: Characterisation (2012).

39. Green, D. . \& Perry, R. H. Perry's Chemical Engineers' Handbook. (McGraw Hill, 2007).

40. Hart, P. W. \& Sommerfeld, J. T. Cost estimation of specialty chemicals from laboratory-scale prices. Cost Eng. 39, 31-35 (1997).

Figure Captions

Figure 1. Conceptual overview of anticipatory assessment inputs to process development

Figure 2. Schematic representation of the CF setup and list of operative conditions and yields of the process for lab and mini-pilot scale

Figure 3. System boundaries: foreground and background system. A picture of the mini-pilot plant is reported in the right-bottom corner

Figure 4. Comparison of the environmental impact of the synthesis of Rufinamide. The results are reported for a conventional batch synthesis, and for the CF synthesis at a lab scale ${ }^{30}$ and a mini-pilot scale. Three scenarios are given for the mini-pilot scale under different yields.

Figure 5. Hotspot analysis of the environmental impact of the CF synthesis of Rufinamide. Three scenarios are reported for the mini-pilot scale (same as in Figure 4) under different yields.

Figure 6. Effects of production technologies, operative conditions and yields on GWP and HTP

Figure 7. Yearly cost of raw materials under different scenarios in the CF process

Figure 8. Cumulative cash flow for different yields in the CF process, and different CAPEX investments 


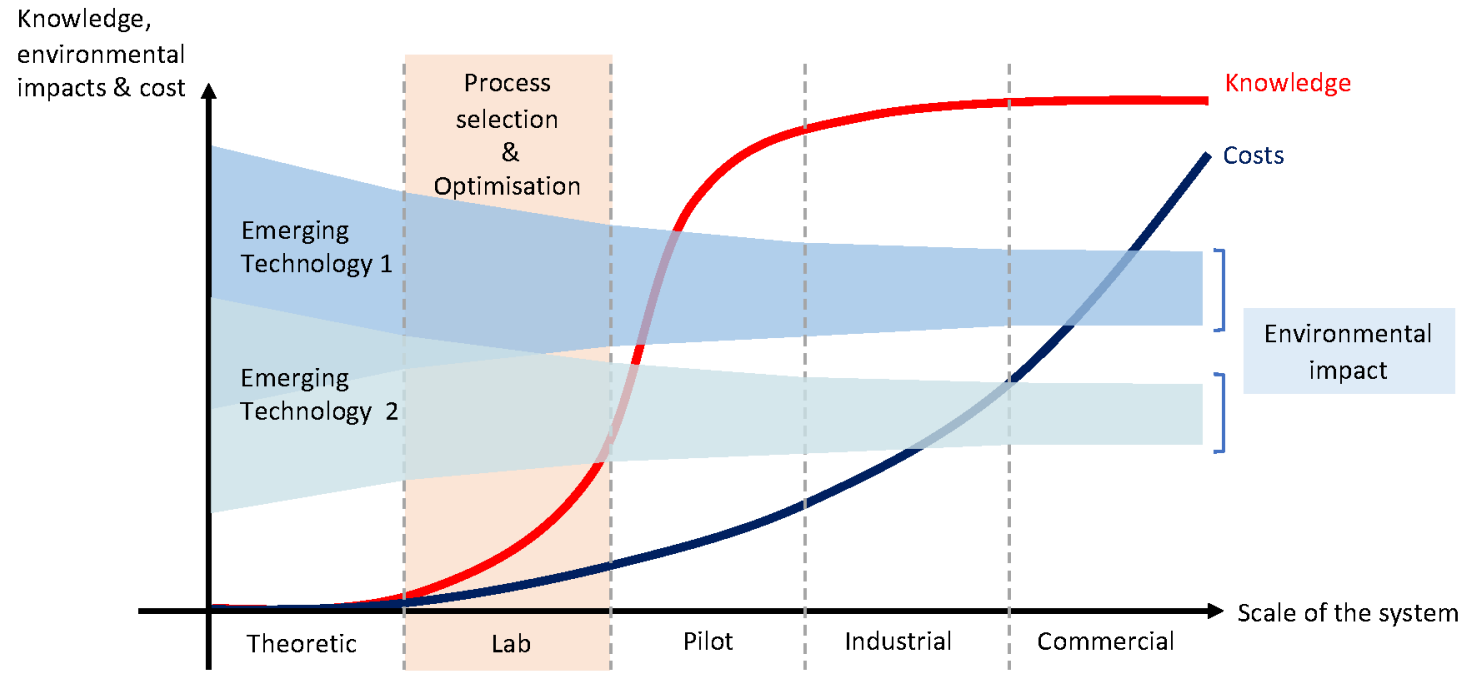

Figure 1 - Conceptual overview of anticipatory assessment inputs to process development 

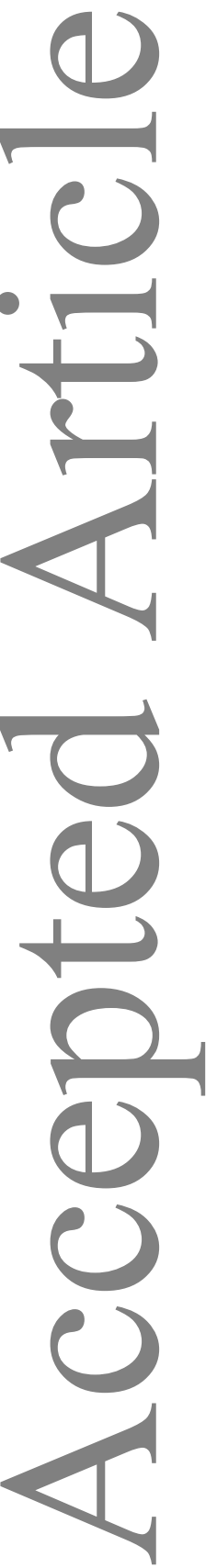
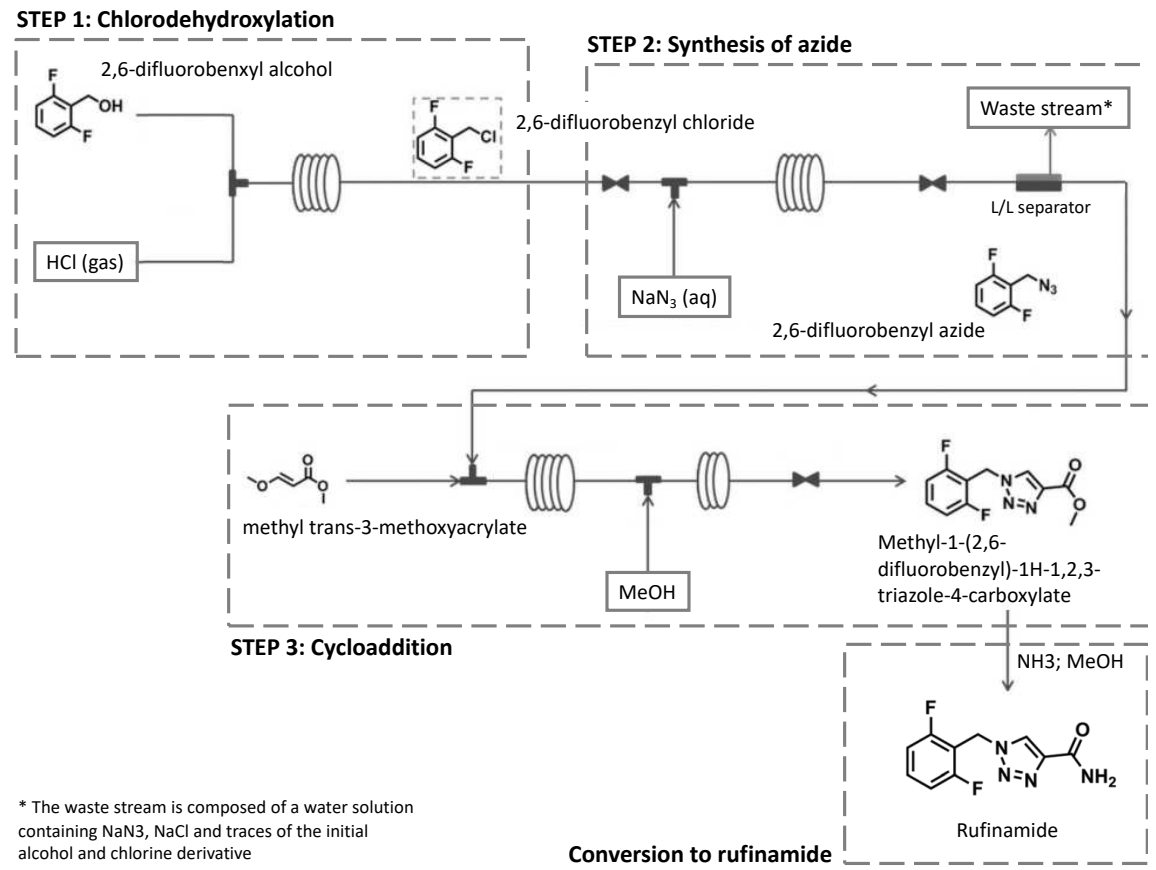

containing $\mathrm{NaN} 3, \mathrm{NaCl}$ and traces of the initial alcohol and chlorine derivative

Conversion to rufinamide

Rufinamide

\begin{tabular}{|c|c|c|c|c|c|c|}
\hline & \multicolumn{2}{|c|}{ Temperature } & \multicolumn{2}{|c|}{ Reactant ratio } & \multicolumn{2}{|c|}{ Step yield } \\
\hline $\begin{array}{l}\text { Synthesis } \\
\text { step }\end{array}$ & $L a b$ & Mini-Pilot & $L a b$ & Mini-Pilot & $L a b$ & Mini-Pilot \\
\hline STEP 1 & $110^{\circ} \mathrm{C}$ & $116^{\circ} \mathrm{C}$ & $\begin{array}{l}\mathrm{HCl}: 2,6 \text {-difluorobenzyl } \\
\text { alcohol=1.2:1 }\end{array}$ & $\begin{array}{l}\mathrm{HCl}: 2,6 \text {-difluorobenzyl } \\
\text { alcohol=4:1 }\end{array}$ & $99 \%$ & $90 \%$ \\
\hline STEP 2 & $160^{\circ} \mathrm{C}$ & $200^{\circ} \mathrm{C}$ & $\begin{array}{c}\text { 2,6-difluorobenzyl } \\
\text { chloride: } \mathrm{NaN}_{3}=1: 1.5\end{array}$ & $\begin{array}{c}\text { 2,6-difluorobenzyl } \\
\text { chloride: } \mathrm{NaN}_{3}=1: 1.6\end{array}$ & $98 \%$ & $>99 \%$ \\
\hline \multirow[t]{2}{*}{ STEP 3} & \multirow[t]{2}{*}{$210^{\circ} \mathrm{C}$} & \multirow[t]{2}{*}{$175^{\circ} \mathrm{C}$} & \multirow[t]{2}{*}{$\begin{array}{l}\text { 2,6-difluorobenzyl } \\
\text { azide:methyl trans-3- } \\
\text { methoxyacrylate=1:5 }\end{array}$} & \multirow[t]{2}{*}{$\begin{array}{c}\text { 2,6-difluorobenzyl } \\
\text { azide:methyl trans-3- } \\
\text { methoxyacrylate=1:1.5 }\end{array}$} & $86 \%$ & $52 \%-93 \%$ \\
\hline & & & & & $\sim 83 \%$ & 47\%-83\% \\
\hline
\end{tabular}

Figure 2 - Schematic representation of the CF setup and list of operative conditions and yields of the process for lab and mini-pilot scale 


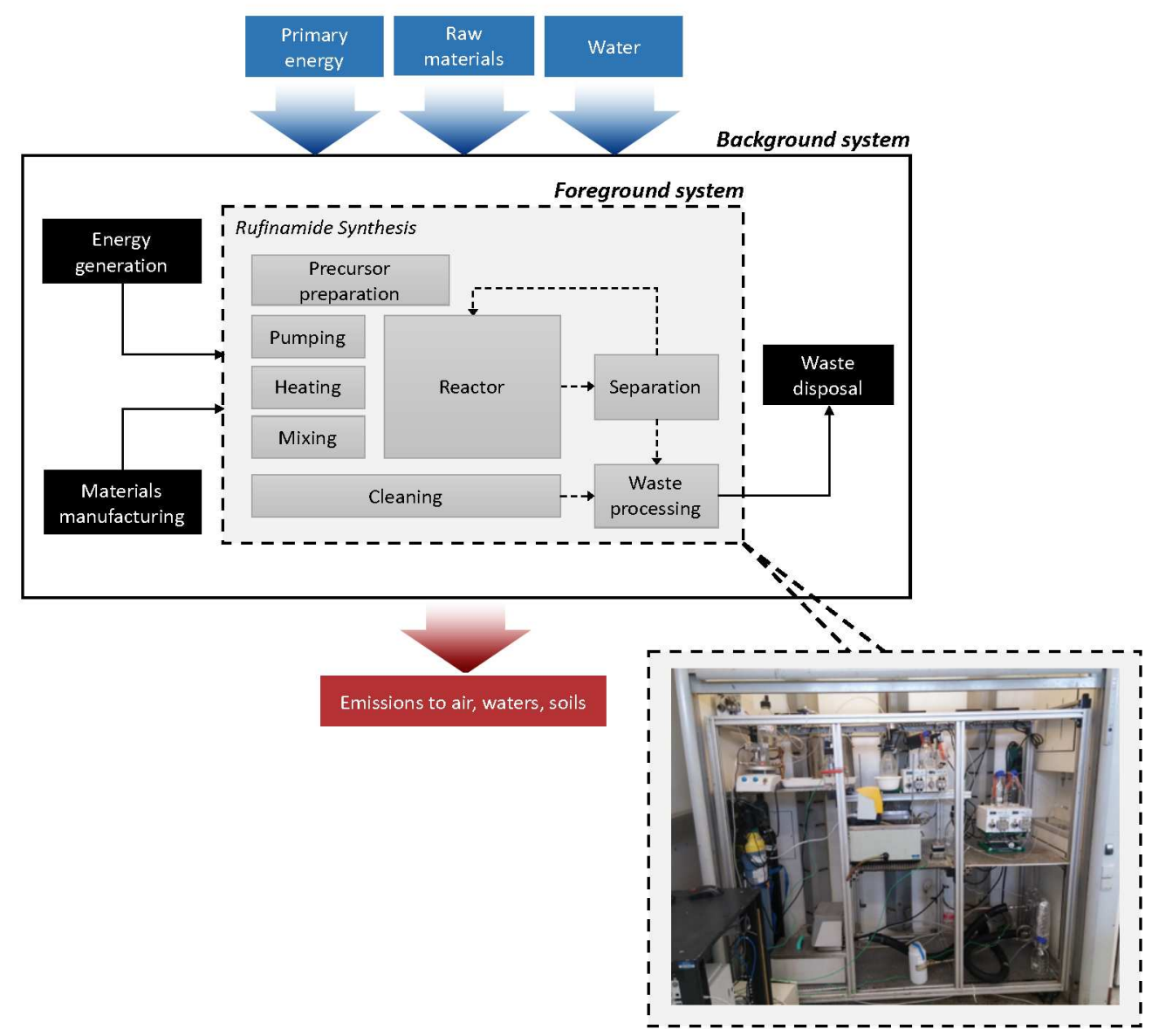

Figure 3 - System boundaries: foreground and background system. A picture of the mini-pilot plant is reported in the right-bottom corner. 


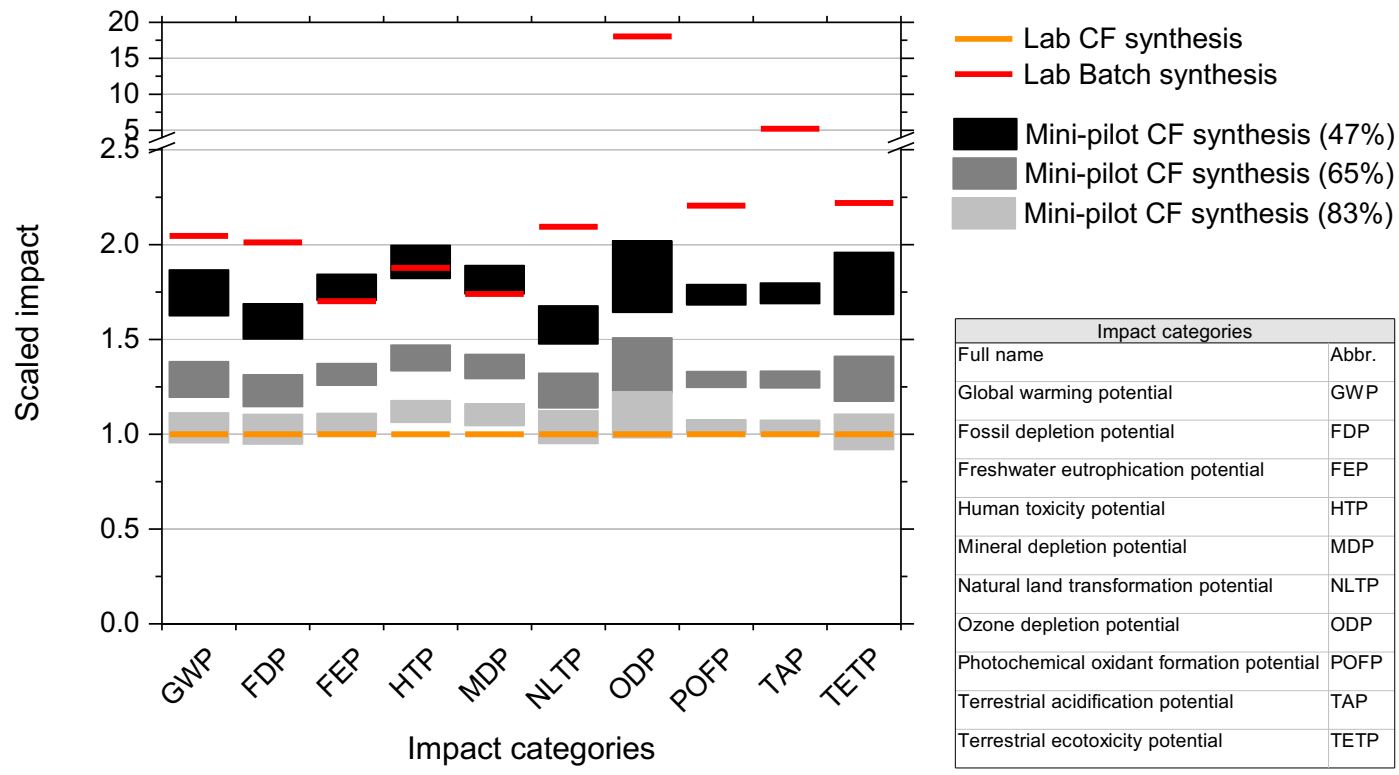

Figure 4-Comparison of the environmental impact of the synthesis of Rufinamide. The results are reported for a conventional batch synthesis, and for the CF synthesis at a lab scale ${ }^{30}$ and a mini-pilot scale. Three scenarios are given for the mini-pilot scale under different yields. 


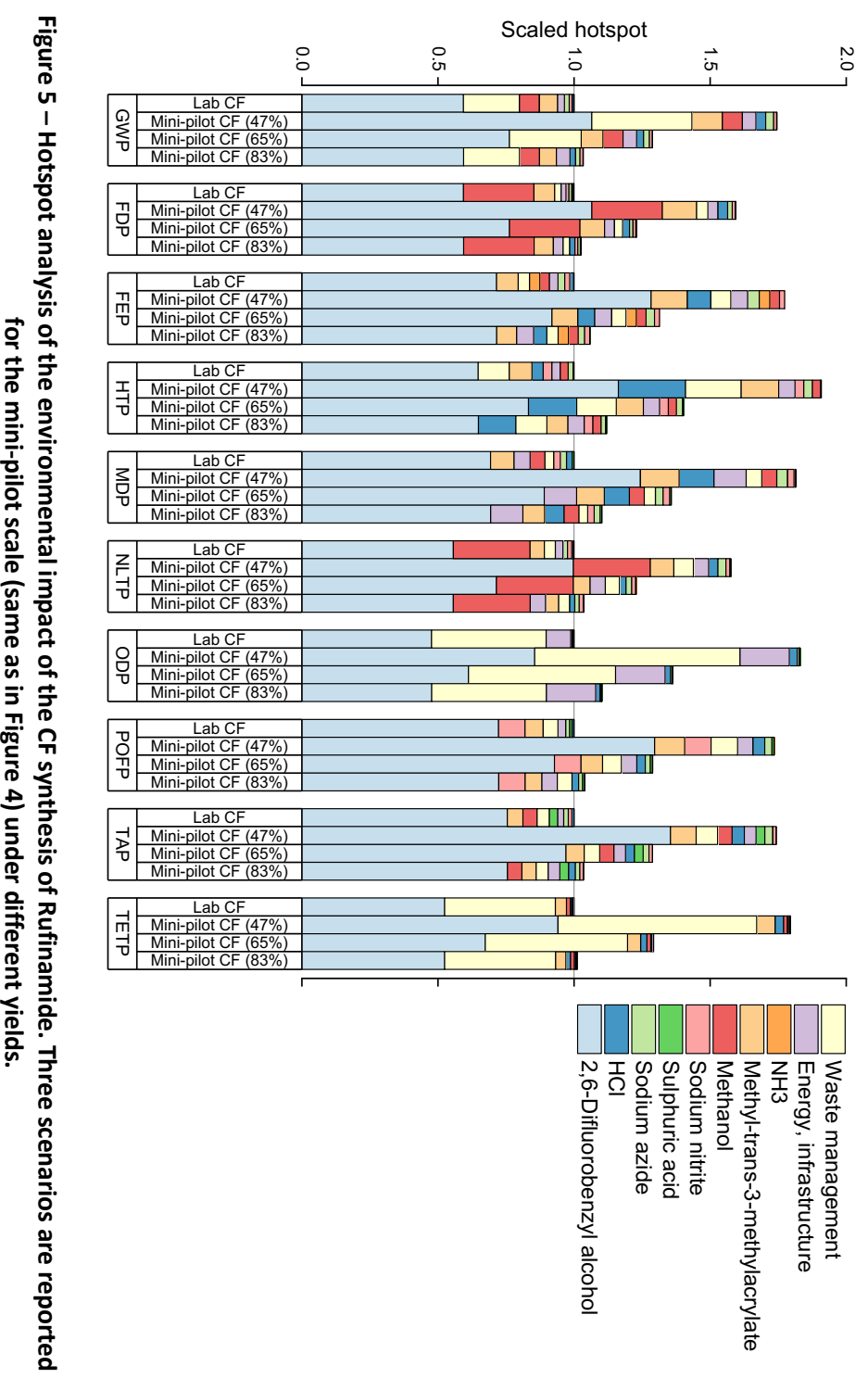

This article is protected by copyright. All rights reserved. 


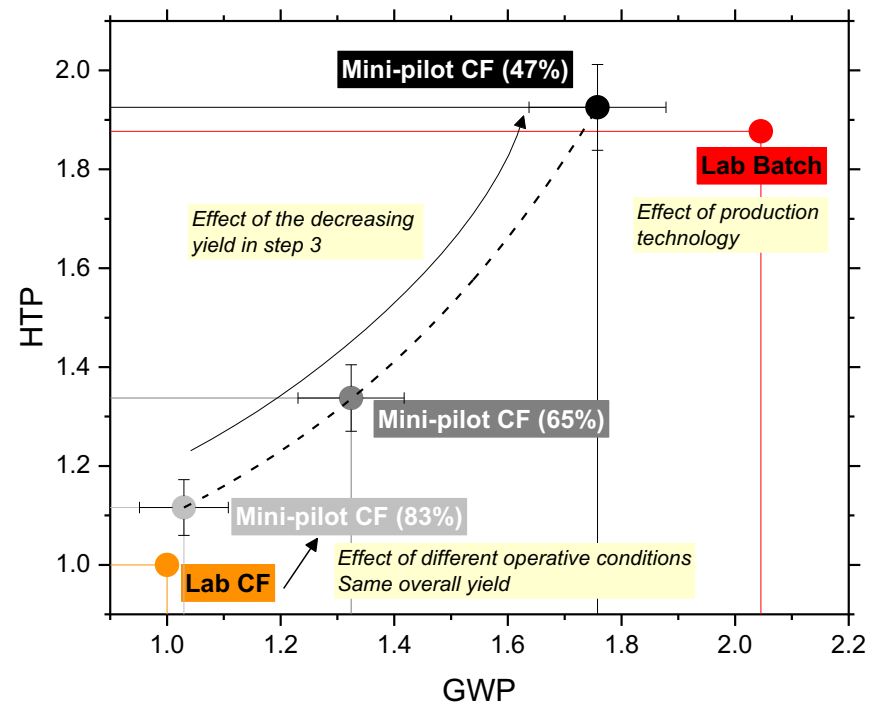

Figure 6 - Effects of production technologies, operative conditions and yields on GWP and HTP 


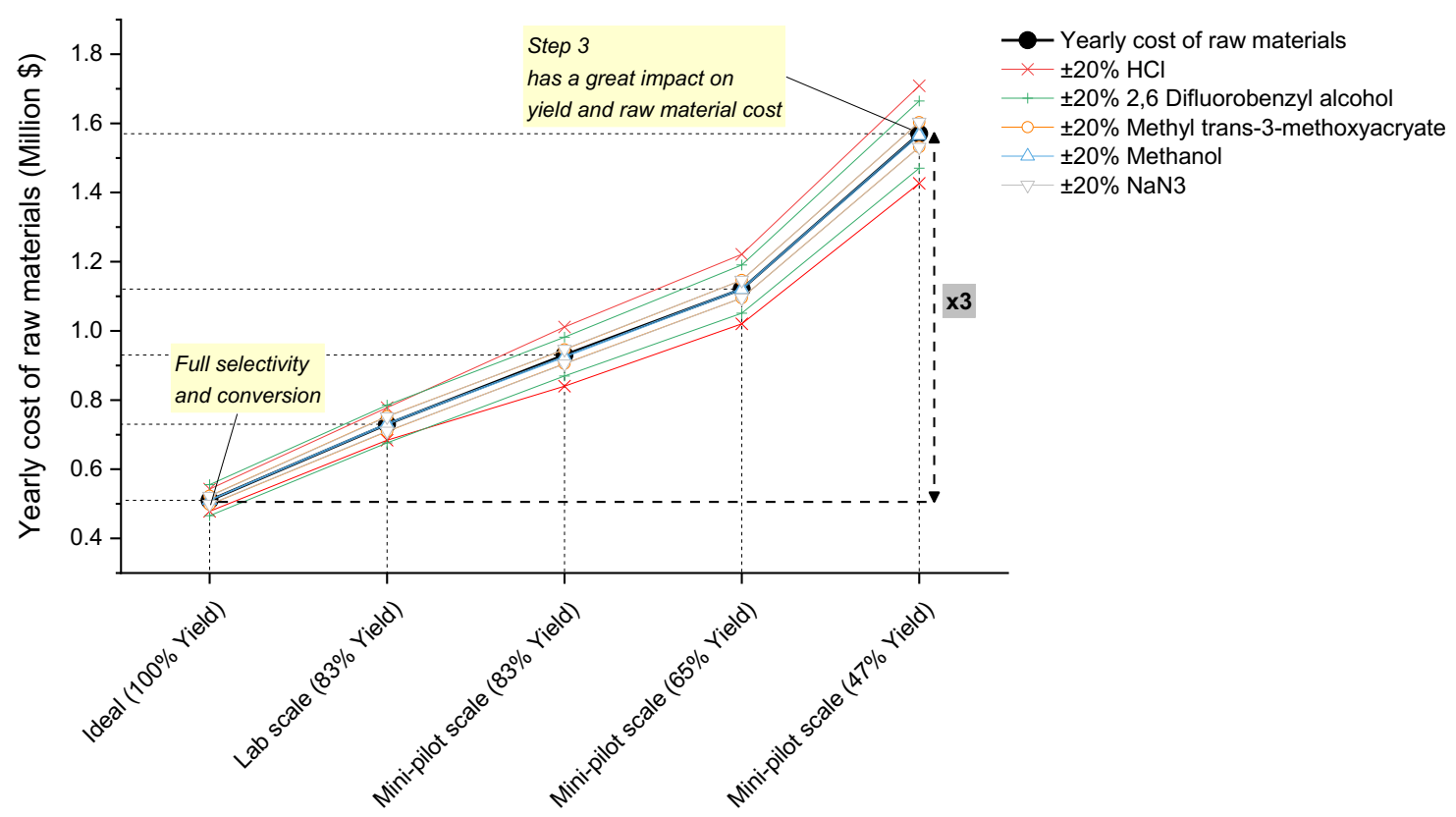

Figure 7 - Yearly cost of raw materials under different scenarios in the CF process 


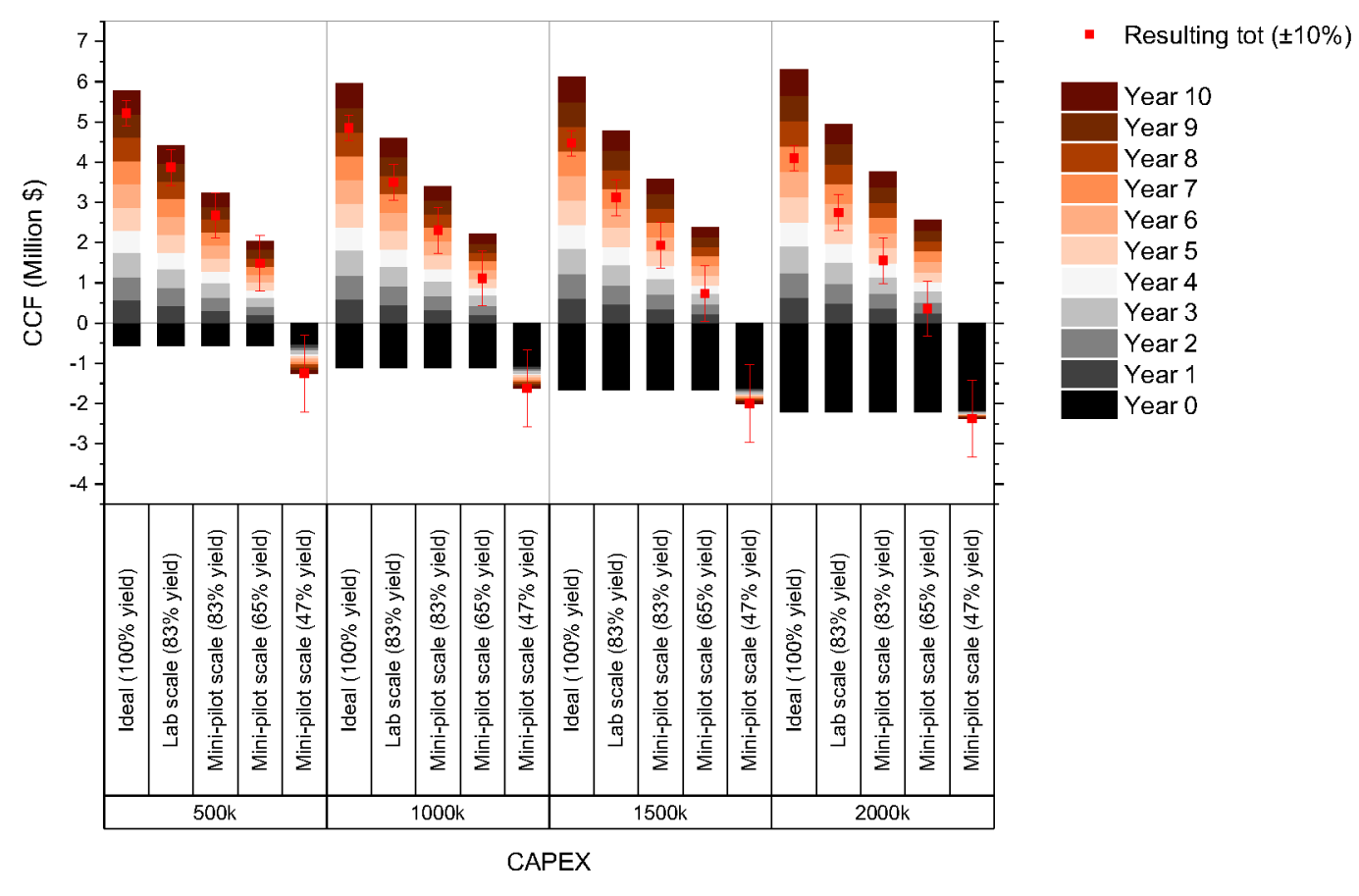

Figure 8 - Cumulative cash flow for different yields in the CF process, and different CAPEX investments 